\title{
Analisis Faktor-Faktor yang Berhubungan dengan Penerapan Organisasi Pembelajar
}

\author{
MAHBUBAH SRIMULATSIH \\ Sekolah Tinggi Ilmu Ekonomi Riau \\ Jln. HR. Subrantas 57 Panam Pekanbaru 28293 Telp. (0761) 63237 \\ Email: mahbubah11nov@gmail.com
}

\begin{abstract}
The objectives on this research are to analyze the relationship between organization culture, senior management commitments, manager skill, employee attitude, organization of work, and human resources as a successful learning organization at PT. Bank Riau Kepri. The research population was 276 employees at the main office of Bank Riau Kepri Pekanbaru and the research samples were 73 employees at the main office of Bank Riau Kepri Pekanbaru from all level and division. A quota sampling was conducted to 73 employees. The primary data collection was conducted by distributing questionnaires and respondents' responses measured using Likert Scale. Descriptive statistics analysis and inferential statistical analysis (partial correlation and multiple linear regression) were used to analyze data in this research. This research's result shows that there is a positive relationship between organization culture, senior management commitments, manager skill, employee attitude, organization of work, and human resources as a successful learning organization.
\end{abstract}

Keywords: learning organization, organization culture, senior management commitments, manager skill, employee attitude, organization of work, and human resources.

Banyaknya organisasi brilian yang mengalami kegagalan dan tidak dapat mempertahankan eksistensinya disebabkan karena organisasi-organisasi tersebut berhenti belajar dan tidak dapat menyesuaikan diri dengan perkembangan jaman dan teknologi. Untuk dapat terus mempertahankan eksistensi dan kinerja organisasi maka dibutuhkan sebuah proses pembelajaran organisasi. Proses pembelajaran dapat dicapai jika organisasi dapat memiliki kemampuan dalam berpikir dan bertindak secara lebih cepat dalam merespon setiap perubahan (Senge, 1990). Organisasi yang mampu melakukan proses pembelajaran tersebut dinamakan dengan organisasi pembelajar.

Penerapan pembelajaran dalam organisasi telah banyak diterapkan di industri perbankan Indonesia.Salah satu industri perbankan tersebut adalah PT.Bank Riau Kepri.Manajemen PT. Bank Riau Kepri berusaha untuk terus melakukan perubahan bagi organisasi ke arah yang lebih baik. Dengan mengusung tekad sebagai penyedia jasa keuangan terkemuka di Provinsi Riau dan Kepri serta di seluruh Sumatra dan bahkan ke depannya seluruh nusantara, maka organisasi ini semakin aktif untuk membentuk sumber daya manusia sebagai sumber daya yang unggul demi kinerja yang baik dikemudian hari.

Penerapan konsep pembelajaran yang selama ini dilakukan oleh PT.Bank Riau Kepri hanya berdasarkan kepada peraturan dan kebijakan yang dibuat oleh manajemen.Dymock dan McCharty (2006) menyatakan bahwa penting bagi organisasi untuk memperhatikan konsep pembelajaran dari sisi persepsi karyawan agar dapat memastikan seperti apa pembelajaran yang diperoleh oleh masingmasing individu di dalam organisasi tersebut sehingga organisasi dapat mengambil keputusan dari perkembangan proses pembelajaran yang telah dilakukan. Aspek pembelajaran dari sisi persepsi karyawan melibatkan faktor-faktor seperti budaya organisasi, komitmen senior manajemen, keahlian pimpinan, sikap karyawan, kerja organisasi, serta program 
dan sumber daya HRD (Ayuup dan Perumai, 2008).

Untuk mengetahui faktor-faktor penting manakah yang memiliki hubungan dengan keberhasilan pembelajaran di dalam organisasi serta melihat faktor mana yang lebih dominan dan berhubungan erat dalam keberhasilan proses pembelajaran yang diterapkan oleh PT. Bank Riau Kepri.

Secara teori bahwa organisasi pembelajar diartikan sebagai organisasi yang memberikan ruang dan kapasitas untuk belajar disetiap tingkatan bagi individu-individu yang bernaung dalam organisasinya (Senge,1990).Pemberian ruang dan kapasitas untuk belajar bagi masing-masing individu penting bagi kemajuan suatu organisasi.Organisasi yang tidak membangun kemampuan belajarnya akan mengalami ketinggalan yang jauh dari organisasi lainnya yang menerapkan sistem pembelajaran.

Hal ini diperkuat oleh pendapat Marquardt (2002) yang menyatakan bahwa untuk mendapatkan dan mempertahankan keunggulan kompetitif, organisasi harus meningkatkan kemampuan mereka belajar dan harus dapat belajar lebih baik dan lebih cepat dari keberhasilan dan kegagalan, dari dalam dan dari luar.

Organisasi pembelajar memiliki dimensi dan karakteristik yang berbeda dengan organisasi yang tidak melakukan pembelajaran. Senge (1990) menyatakan bahwa organisasi pembelajar memiliki lima dimensi yaitu keahlian pribadi, model mental, berbagi visi, pembelajaran dalam tim dan berpikir sistem. Watkins dan Marsick (2003) berpendapat bahwa terdapat tujuh dimensi organisasi pembelajar yaitu continuous learning, inquiry and dialog, team learning, empowerment, embedded system, system connection, dan strategic ledership. Lebih lanjut, Marquardt (2002) menjelaskan lima model organasisasi pembelajar yang terdiri dari pembelajaran (learning), organisasi (organization), anggota organisasi (people), pengetahuan (knowledge), dan teknologi (technology). Kesemua dimensi ini diperlukan untuk memaksimalkan pembelajaran pada organisasi sehingga dapat terbentuk suatu organisasi pembelajar yang sukses dan berhasil.

Kemudian Katz dan Kahn dalam Schein (1990) dalam tulisan mereka di edisi kedua The Social Psychology of Organizations menyatakan bahwa budaya organisasi merupakan peran,norma, dan nilai-nilai dalam organisasi yang mempengaruhi iklim dan kebudayaan sebagai konsepeksplisit. Schein (1990) mendefinisikan budaya organisasi sebagai pola dasar asumsi yang dikembangkan oleh organisasi dalam rangka untuk menyelesaikan permasalahan baik internal maupun eksternal dan diajarkan kepada semua individu dalam organisasi sebagai cara untuk melihat, berpikir dan berpandangan selama berada dalam orgnisasi tersebut.Hal ini menunjukkan bahwa keutamaan budaya organisasi adalah sebagai pengendali dan arah dalam membentuk sikap dan perilaku manusia yang melibatkan diri dalam suatu kegiatan organisasi.

Peran senior manajemen merupakan pondasi dari terbentuknya suatu organisasi. Komitmen manajemen/pimpinan puncak sangat berhubungan erat dengan keputusan akan keinginan untuk berubah dan belajar menuju kesuksesan organisasi. Selain itu, penerapan dan implementasi pembelajaran organisasi harus datang dari pihak manajemen atas yang pada akhirnya disampaikan kepada setiap karyawan dan entitas yang ada di dalam organisasi untuk dipelajari karena peran senior manajemen adalah sebagai guru, perancang dan pengurus yang memiliki tanggung jawab terhadap pembelajaran (Senge, 1990).

Menurut Rijal (2009), keahlian pimpinan/manajer merupakan keahlian seseorang dalam memotivasi individu/stafnya menuju visi bersama, melakukan perubahan model mental dan mendorong lingkungan untuk terus belajar. Dengan keahlian yang terus menerus maju dan berkembang, mereka

$$
\text { p.ISSN: 2407-800X e.ISSN: 2541-4356 }
$$


dapat membantu stafnya untuk meraih tujuan yang diinginkan dalam proses pembelajaran mereka. Pada dasarnya training/pelatihan juga membantu para manajer untuk meningkatkan kemampuan dan keahlian mereka yang akan dibutuhkan di masa yang akan datang. Untuk mendapatkan hasil yang efektif, manajer butuh untuk mengidentifikasi keahlian dan kemampuan yang dimiliki oleh staf mereka saat ini serta keahlian apa yang mereka butuhkan dalam periode pendek ataupun dalam periode panjang dan merencakan serta menyusun rencana untuk mendapatkan hasil yang diinginkan (Ayupp dan Perumai, 2008).

Chong dan Choi (2005) menggambarkan bahwa karyawan memiliki kontribusi yang besar terhadap tujuan organisasi. Dengan kata lain, karyawan dan sikap yang ditunjukkan di dalam menyelesaikan tanggung jawab pekerjaan mereka berpengaruh langsung terhadap keberhasilan pembelajaran di dalam organisasi. (Pailis et al., 2016) menyebutkan bahwa sikap seorang karyawan didasari pada konsep dirinya: "self-concept in trying fosters courage in taking risks".

Lebih lanjut, Lassey dalam Ayupp dan Perumai (2008) menyatakan bahwa perubahan sikap seorang individu di dalam tingkah lakunya memiliki efek atau dampak bagi individu-individu lainnya di dalam organisasi. Oleh karena itu setiap individu yang ada di dalam organisasi membutuhkan komitmen dari dalam dirinya untuk dapat saling membantu dan berbagi dalam proses pembelajaran sehingga keberhasilan pembelajaran organisasi dapat di raih dengan lebih maksimal.

Kerja organisasi merupakan sebuah sistem dan prosedur yang mentransformasikan input ke output dan dipengaruhi oleh peraturan-peraturan organisasi, perilaku sosial, nilai-nilai budaya, kekuatan formal dan informal (Sauter dan Watson dalam Ayupp dan Perumai, 2008).Seperti yang dijelaskan oleh Thompson dan Warhurst dalam Ayupp dan Perumai (2008) bahwasanya perubahan struktur kerja bisa dilihat sebagai penawaran bagi para pekerja dan karyawan sebagai kesempatan untuk mendapatkan kemampuan yang lebih, fleksibilitas dalam bekerja dan perubahan komitmen terhadap organisasi sehingga dapat meningkatkan kemampuan daya saing dari organisasi. Untuk mendapatkan hal-hal tersebut, pembelajaran harus menjadi solusi baru dalam menyelesaikan permaalahan-permasalahan yang tidak dimengerti sehingga dikemudian hari kerja organisasi memberikan dampak yang lebih baik dalam proses pembelajaran organisasi.

SDM yang kompeten sebagian besar dibentuk oleh departemen HR Departemen HR di dalam organisasi yang belajar akan menciptakan komitmen yang kuat terhadap penyediaan keuangan dan sumber daya manusia untuk meningkatkan kualitas pembelajaran dari setiap staf/karyawan di dalam organisasi (Marquardt, 2002).

Lassey dalam Ayupp dan Perumai (2008) menyebutkan bahwa pendekatan yang fleksibel dalam melatih dan memajukan sumber daya manusia adalah dengan menciptakan perencanaanperencanaan yang matang bagi kebutuhan tiap individu yang ada di dalam organisasi. Dengan perencanaan yang matang diharapkan dapat memberikan solusi akan kebutuhan mereka.

\section{METODE}

Pengumpulan data dilakukan
dengan menggunakan metoda survei dengan menggunakan alat bantu kuesioner yang disebar kepada 73 orang karyawan Bank Riau Kepri dari berbagai level dan divisi.Untuk menentukan sampel yang dibutuhkan dalam penelitian ini

Analisis statistik inferensial adalah dengan menggunakan analisis korelasi parsial dan regresi berganda. Dalam analisis regresi akan dilakukan uji Anova, uji $\mathrm{R}$ Square, uji t, dan uji signifikansi..

p.ISSN: 2407-800X e.ISSN: 2541-4356 
HASIL

Total responden berjumlah 73 orang karyawan kantor pusat PT.Bank Riau Kepri. Mayoritas respondenberjenis kelamin lakilaki sebanyak $61,6 \%$ dan perempuan sebanyak 38,4\%. Berdasarkan usia, mayoritas responden berusia 20-30 Tahun sebanyak 50,7 \% , responden berusia 31-40 tahun sebanyak $45,2 \%$, responden berusia 41-50 tahun sebanyak $2,7 \%$ dan responden berusia $>50$ tahun sebanyak $1,4 \%$. Berdasarkan tingkat pendidikan $80,8 \%$ berpendidikan $\mathrm{S} 1,11 \%$ berlatar belakang pendidikan Diploma dan 8,2\% berpendidakan S2/S3. Berdasarkan posisi kerja, sebanyak $49,3 \%$ responden sebagai pelaksana, $37 \%$ responden sebagai pinsi (pemimpin seksi)dan $13,7 \%$ responden sebagai pemimpin divisi. Sebanyak 54,8\% responden memiliki masa kerja kurang dari 5 tahun, 39,7\% responden memiliki masa kerja 5-10 tahun, dan masing-masing 2,7\% memiliki masa kerja 11-15 tahun dan lebih dari 15 tahun.

Setelah dilakukananalisis statistik inferensial menggunakan analisis regresi berganda dapat ditarik kesimpulan sebagai berikut:

\begin{tabular}{|l|l|l|l|}
\hline Hipotesis & Sig. & $\begin{array}{l}\text { Koefisien } \\
\text { Korelasi }\end{array}$ & Ket. \\
\hline $\begin{array}{l}\text { Budaya } \\
\text { organisasi } \\
\text { memiliki } \\
\text { hubungan } \\
\text { positif dengan } \\
\text { keberhasilan } \\
\text { organisasi } \\
\text { pembelajar }\end{array}$ & 0,038 & 0.2530 & $\begin{array}{l}\mathrm{H} 1 \\
\text { diterima }\end{array}$ \\
\hline $\begin{array}{l}\text { Komitmen } \\
\text { senior } \\
\text { manajemen } \\
\text { memiliki } \\
\text { hubungan } \\
\text { positif dengan } \\
\text { keberhasilan } \\
\text { organisasi } \\
\text { pembelajar }\end{array}$ & 0,007 & 0.3250 & $\mathrm{H} 2$ \\
\hline $\begin{array}{l}\text { Keahlian } \\
\text { pimpinan }\end{array}$ & 0,009 & 0.3140 & diterima \\
\hline
\end{tabular}

\begin{tabular}{|l|l|l|l|}
\hline Hipotesis & Sig. & $\begin{array}{l}\text { Koefisien } \\
\text { Korelasi }\end{array}$ & Ket. \\
\hline $\begin{array}{l}\text { memiliki } \\
\text { hubungan } \\
\text { positif dengan } \\
\text { keberhasilan } \\
\text { organisasi } \\
\text { pembelajar }\end{array}$ & & $\begin{array}{l}\text { H3 } \\
\text { diterima }\end{array}$ \\
\hline $\begin{array}{l}\text { Sikap } \\
\text { karyawan } \\
\text { memiliki } \\
\text { hubungan } \\
\text { positif dengan } \\
\text { keberhasilan } \\
\text { organisasi } \\
\text { pembelajar }\end{array}$ & 0,018 & 0.2870 & $\begin{array}{l}\text { H4 } \\
\text { diterima }\end{array}$ \\
\hline $\begin{array}{l}\text { Kerja } \\
\text { organisasi } \\
\text { memiliki } \\
\text { hubungan } \\
\text { positif dengan } \\
\text { keberhasilan } \\
\text { organisasi } \\
\text { pembelajar }\end{array}$ & 0,036 & 0.2540 & H5 \\
\hline $\begin{array}{l}\text { Program dan } \\
\text { sumber daya } \\
\text { departemen } \\
\text { HR memiliki } \\
\text { hubungan } \\
\text { positif dengan } \\
\text { keberhasilan } \\
\text { organisasi } \\
\text { pembelajar }\end{array}$ & 0,008 & 0.3200 & $\begin{array}{l}\text { H6 } \\
\text { diterima }\end{array}$ \\
\hline & & & \\
\hline
\end{tabular}

\section{PEMBAHASAN}

Dari tabel di atas dapat terlihat bahwa hipotesis pertama terbukti, bahwa budaya organisasi memiliki hubungan positif dengan keberhasilan organisasi pembelajar. Penerapan budaya organisasi yang dapat mengkomunikasikan tujuan masing-masing pihak di dalam internal ataupun eksternal organisasi dapat diaplikasikan oleh PT.Bank Riau Kepri. Hal ini sejalan dengan temuan Singh (2010) yang menyatakan bahwa budaya organisasi yang mendukung dan memfasilitasi pembelajaran akan menghasilkan dampak positif bagi organisasi di masa yang akan 
datang.

Hasil uji regresi menyatakan bahwa hipotesis kedua terbukti, komitmen senior manajemen memiliki hubungan positif dengan keberhasilan organisasi pembelajar. Implementasi pembelajaran organisasi yang datang dari pihak manajemen atas PT.Bank Riau Kepri disampaikan kepada setiap karyawan dan entitas yang ada di dalam organisasi ini untuk dipelajari dan diberi perhatian terhadap proses pembelajaran tersebut.

Hal ini sejalan dengan peran senior manajer sebagai guru, designer, dan pengurus yang mempunyai tanggung jawab terhadap pembelajaran (Senge, 1990). Faktor budaya Indonesia yang berhubungan dengan jarak kekuasaan yang tinggi menyebabkan hipotesis kedua menjadi faktor paling dominan dalam penelitian ini. Bawahan/karyawan akan melihat bahwa kebijakan senior manajemen sebagai sesuatu yang penting di dalam penerimaan proses pembelajaran yang terjadi di organisasi. Dalam internal organisasi PT. Bank Riau Kepri, bawahan/karyawan akan sangat dipengaruhi oleh kebijakan yang diciptakan oleh senior manajemen dalam menunjukkan perilaku yang menuju ke arah perubahan dan tindakan yang di ambil. Komitmen senior mananejemen memegang peranan yang sangat vital dan penting di dalam organisasi pembelajar dimana komitmen yang ditunjukkan oleh senior manajemen dapat memotivasi bawahan/karyawan dalam berbagi visi dan misi, perubahan model mental dan membantu perkembangan lingkungan pembelajaran (Senge, 1990).

Hasil uji regresi menunjukkan bahwa keahlian pimpinan berhubungan positif dengan keberhasilan organisasi pembelajar. Di PT. Bank Riau Kepri, pimpinan berperan penting dalam mendukung dan mendorong karyawannya untuk belajar, berbagi dan memanfaatkan pengetahuan secara bersamasama demi keberhasilan pembelajaran di dalam organisasi yang pada akhirnya menciptakan kinerja organisasi yang positif. Selain itu faktor budaya dimana pimpinan yang memiliki andil tinggi terhadap keberhasilan organisasi akan diikuti oleh bawahan terutama di negara yang memiliki dimensi budaya jarak kekuasaan yang tinggi yaitu dengan kepemimpinan yang bersifat patrenalistik.

Hasil analisis uji regresi menunjukkan bahwa sikap karyawan berhubungan positif dengan organisasi pembelajar. Dalam penelitian ini, organisasi menyadari bahwa karyawan merupakan aset yang sangat penting di dalam suatu organisasi. Karyawan memiliki kemampuan untuk dapat menerima dan mengaplikasikan proses pembelajaran tersebut ke dalam pekerjaan mereka masing-masing. Hal ini sejalan dengan pendapat Sudharatna dan Laubie (2009) yang menyimpulkan bahwa karakteristik atau sikap karyawan merupakan salah satu ukuran penting bagi terciptanya keberhasilan organisasi. Selain itu faktor budaya Indonesia dengan dimensi jarak kekuasaan yang tinggi menyebabkan karyawan menjadi lebih disiplin dan takut akan kekuasaan atasan dan tingginya nilai kolektivisme dibandingkan nilai individualisme, maka menyebabkan karyawan juga lebih mudah untuk berkomitmen dalam melaksanakan tugastugas yang diberikan oleh atasan.

Hasil analisis uji regresi diketahui bahwa hipotesis kelima terbukti, bahwa kerja organisasi memiliki hubungan positif dengan keberhasilan organisasi pembelajar. PT. Bank Riau Kepri menerapkan strategi organisasi dengan mereorganisasi struktur organisasi perusahaan guna mengembangkan aktivitas usaha yang lebih proaktif dan responsif terhadap tuntutan pasar.PT.Bank Riau Kepri melihat bahwa meredefinisikan strategi bisnis yang baru merupakan salah satu faktor kerja organisasi yang memiliki hubungan yang erat dengan keberhasilan pembelajaran organisasi tersebut.

Hasil analisis uji regresi menyatakan hipotesis keenamjuga terbukti, bahwa sumber daya dan program HRD memiliki hubungan positif dengan keberhasilan organisasi pembelajar. PT.Bank Riau Keprimendapatkan karyawan

p.ISSN: $2407-800 X \quad$ e.ISSN: $2541-4356$ 
dari proses seleksi penerimaan dan mengambil orang-orang yang berkompeten di bidangnya masing-masing dengan meneruskan pembelajaran terhadap mereka dan mengeksplor lebih lanjut lagi potensi yang mereka miliki melalui berbagai proses pembelajaran yang ada. Hubungan yang berkaitan dengan budaya Indonesia dimana adanya ketidakpastian yang sedikit tinggi cenderung menjunjung tinggi konformitas dan keamanan, menghindari resiko dan lebih mengandalkan peraturan formal yang dalam hal ini dirancang oleh organisasi juga membuktikan bahwa program-program departemen SDM di PT.Bank Riau Kepri merupakan salah satu faktor dalam keberhasilan organisasi pembelajar.

\section{SIMPULAN}

Konsep pembelajaransecara terusmenerus yang diusung oleh PT. Bank Riau Kepri maka diperlukan adanya pembentukan Learning Center dan E-Learning yang dapat berfungsi meningkatkan kemampuan pembelajaran karyawan dengan lebih baik lagi dan mendukung konsep pembelajaran organisasi.Selain itu, perusahaan dapat membangun kesempatan lebih banyak lagi bagi karyawan untuk ikut terlibat dalam diskusi (iklim dialog dan knowledge sharing) yang berkaitan dengan pengambilan keputusan atau kebijakan perusahaan sehubungan dengan pembelajaran organisasi. Lebih lanjut lagi, perusahaan dapat mengadakan survei baik secara formal ataupun informal untuk mengetahui persepsi karyawan terhadap konsep pembelajaran yang diterapkan oleh organisasi.

Karyawan juga dapat memberikan saran dan umpan balik akan proses pembelajaran yang diterima serta konsep pembelajaran yang seperti apa yang dapat dengan lebih mudah dikembangkan di dalam organisasi. Pembelajaran organisasi dapat menjadi lebih baik lagi dengan mempertimbangkan faktor-faktor dimensi budaya Indonesia karena tidak dapat dipungkiri bahwa budaya menjadi aspek penting dalam keberhasilam organisasi kedepannya.

\section{DAFTAR RUJUKAN}

Ayupp, K and Perumai, A. (2008).Learning Organization: Exploring Employee Perception. The Icfai University Journal of Behavior Vol.VII No.3 pp. 22-32

Bungin, B. (2004).Metodologi Penelitian Kuantitatif Ed.1. Kencana, Jakarta.

Chong, S.C and Choi, YY.S. (2005). Critical Factors In The Succesful Implementation of Knowledge Management. Journal of Knowledge Management Practice. California State University, USA.

Cooper, D.R and Schindler, P.S. (2011). Business Research Method. $11^{\text {th }}$ Edition, McGraw Hill Higher Education. New York, USA.

Darami, A. (1998). Learning Organization Practices: A Profile of SKF Bearing Industries (Malaysia) SDN. BHD.A Thesis. Universiti Putra Malaysia, Malaysia

Dymock, D and Mc.Charty, C. (2006). Towards a learning organization? Employee perceptions. The Learning Organization Vol. 13, No. 5. pp 525-536.Emerald Group Publishing Limited. www.emeraldinsight.com

Edmonson, A and Moingeon, B. (1996). From Organizational Learning to Learning Organization. Essential Readings in Management Trainings. Pp 21-34

Edmonson, $\mathrm{A}$ and Moingeon, B. (1996).Learning Organization and Competitive Advantage.Biddles Ltd, Guildford, Surrey, Great Britain. 
Garvin, D.A. (1993). Building Learning Organization.Harvard Business Review 71, No.4. pp 78-91. Hardvard Business School Press, Boston. MA.

Garvin, D.A. (2000). Learning in Action: A guide to putting the learning organization to work. Hardvard Business School Press, Boston. MA.

Hofstede, G. 1986, Culture's Consequences, International Differences in Work Related Values. Sage Publication, Beverly Hills/London/New Delhi.

Hoon, J.S. (2008). The effect of learning organization culture on the practices of human knowledge creation: an empirical research study in Korea. International Journal of Training and Development 12:4

Hoon, J.S, Joo. B and J, T.C. (2009).The dimension of learning questionnaire (DLOQ): A Validation Studyin a Korean Context. Human Resource Development Quarterly 20, No. 1 pp 43-61. Willy Periodicals, Inc.Published online in Wiley InterScience

(www.interscience.wiley.com)

Jogiyanto.(2010). Metodologi Penelitian Bisnis. BPFE, Yogyakarta.

Juceviciene, $\mathrm{P}$ and Leonaviciene, R. (2007).The Change of Human Resource Development Concepts in the Process of Becoming a Learning Organization. Journal of Economics and Management 12 pp 569-575. Kaunas University of Technology. Lithuania.

Kline, P and Saunder, B. (1993).Ten Steps to $a$ Learning Organization.Great Ocean Publishers, Arlington, Virginia.
Malhotra, Y. (1996). Organizational Learning and Learning Organizations: An Overviewhttp://www.brint.com/pa pers/orglrng.htm

Marsick, V.J and Watkins, K.E. (2003). Demonstrating the value of an organization's learning culture: the dimension of the Learning Organization Questionnaire, Advances in Developing Human Resources, Vol. 11 No. 2. Downloaded by Ramesh Srinivashan from http://adh.sagepub.com

Marquardt M.J. (2002). Building the Learning Organization: A Systems Approach to Quantum Improvement and Global Success second edition. Mc Graw - Hill, London.

Mishra, B. and Uday, A.B. (2010).Empowerment: A necessary Attribute of A Learning Organization?.Organizations and Markets in Emerging Economies, Vol.1, No.2. pp 48-70. Asia Pacific Institute and International Management Institute, India

Pailis, E. A., Suroto, B., Hadiyati and Fatkhurahman (2016) 'The Influence of Partnerships and Selfconcept for the Courage to Take Risks and Their Impact on the Achievements Sought of Small Industries in the City of Pekanbaru', American Journal of Economic, 6(5), pp. 262-269. doi: 10.5923/j.economics.20160605.03.

Pedler, M., Burgoyne, J.D and Boydell, T. (1991).The Learning Company. Mc Graw - Hill, London.

Priyatno, D. (2010). Teknik Mudah dan Cepat Melakukan Analisis Data 
Penelitian dengan SPSS. Gava Media, Yogyakarta.

Putri, A.U. (2009). Identifikasi Penerapan Model Sistem Organisasi Pembelajar pada PT. TASPEN (Persero) Cabang Bogor.Skripsi.IPB, Bogor.

Rijal, S. (2009).Leading the Learning Organization.BusinessEducation and Acreditation, Vol.1 No.1. Purbanchal University, India.

Robbin, S.P. (1997). Perilaku Organisasi Buku 1. Salemba Empat, Jakarta.

Sambrook, S. (2002).Factors Influencing Learning in Work: A Comparison of Two Research Projects (European and United Kingdom Based,EuropeanEducational Research Journal, Vol.1, No.3 pp 552-537. University of Wales, Bangor.UK.

Schein, E. (1990). Organizational Culture.American Psychologist, Vol. 45, February, pp.109-19.

Sekaran, U. (2003). Research Methods ForBusiness, $4^{\text {th }}$ Edition. John Wiley and Sons, New York

Senge, P.M. (1990). The fifth disciplines: the art and practice of the learning organization. Doubleday Currency, New York.

Singh, K. (2010). An Analysis of Relationship between the Learning Organization and Organization Culture in Indian Business

Organization.Organizations and Markets in Emerging Economies 1, No. 1 pp 142-165.University of Delhi, India.

Skennar, A. (2009). Establishing and Building a Learning Culture in an
Organisation. Training \& Development in Australia.

Sudharatna, Y. and Laubie, Li. (2003).An Organization's Readiness to Change towards the Development of $a$ Learning Organization.Organizational Learning and Knowledge, $5^{\text {th }}$ International Conference. Australia.

Sugiyono (2010).Statistika Untuk Penelitian. Alfabeta, Bandung.

Watkins, K.E and Marsick, V.J(1999).Dimension of the Learning Organization Questionnaire.Jossey - Bass, San Fransisco, USA.

Yang, B., Watkins, K.E and Marsick, V.J. (2004).The Construct of the Learning Organization: Dimensions, Measurement, and Validation. Human Resource Development Quarterly15, No. 1 pp 31-55.

Yohana, S.L dan Fitriati, R. (2009).Pengaruh Organisasi Pembelajar terhadap Kompetensi Pegawai Bank.Bisnis dan Birokrasi,Jurnal Ilmu Administrasi dan Organisasi Vol.16, No.1 hlm 25-35. 